\title{
Development of Non-technical Skills in a Multicultural Environment: Case study in Latvia
}

\author{
Rudite Andersone ${ }^{1}$, Gatis Lama ${ }^{2}$, Dita Raiska ${ }^{3}$ \\ ${ }^{1}$ Professor, University of Latvia, Latvia \\ ${ }^{2,3} \mathrm{PhD}$ students, University of Latvia, Latvia
}

\begin{abstract}
The world today is characterized by globalization, rapid development of information technologies, a multicultural environment and a diversity of values resulting from active human migration and cultural exchanges. Today's pupils will have to create an unprecedented, new economic, political, social and cultural environment in the future. The World Economic Forum foresees that $65 \%$ of young people who are starting school at the moment will be employed in a profession that does not exist today. Therefore, in today's multi-cultural workplace, it is becoming increasingly important for an individual not only to have concrete skills to carry out his or her direct work duties, but also to his or her non-technical or transversal skills, i.e. to communicate and interact with other people in all areas of human activity, to make decisions independently, etc. Non-technical or transversal skills, largely determine the competitiveness of each member of the society and the development of society as a whole. The aim of the article is to analyze the assessment of non-technical skills in a multicultural society at different stages of education (for pupils and students) and in the workplace (for teachers and other professionals). A survey of 257 respondents was conducted for this purpose. The survey results show that non-technical skills ratings for teachers and other professionals are generally higher than for pupils and students. Respondents say they are actively pursuing the development of their communication and collaboration skills, and less the decision-making skills. The respondents say to achieve this by taking part in day-to-day training and the working environment in the multicultural community, in group or team work, in social projects, and by reading literature, attending further training courses, etc.
\end{abstract}

Keywords: non-technical skills, multicultural environment 


\section{Introduction}

Multiculturalism is the reality of the contemporary world - there is no country, no society that the migration processes have not influenced. Thus, various racial and ethnic groups with different histories, languages, culture and religion live together within national-political borders. These days, turbulent political change processes have to be taken into account: British political advisor Robert Cooper admits that borders between postmodern countries are disappearing due to technological developments and the rapid process of globalization (Cooper, 2003).

The geopolitical processes of recent years in Latvia and the world have activated migration processes, which take place both in terms of globalization and economic and political factors, and which lead to interaction between various ethnic groups and cultures. Migration is not an unambiguous process. On one hand, it can be seen as a positive phenomenon which helps to address the demographic challenges of the beneficiary country and contributes significantly to the development of its economic and cultural processes. On the other hand, immigrants are often perceived as a burden or even threat to the recipient country, by creating too heavy a social burden and competing with locals regarding employment and changing the multicultural environment that has already developed in that particular society. The multicultural perspective provides a conceptual frame that distinguishes and highlights the complex process of diversity that prevails in society while ensuring coherence and collaboration, bringing together people with different cultural backgrounds. Over the past 20 years, multiculturalism has been recognized as a powerful tool, not only to understand groups of unfamiliar people, but also to better understand ourselves and those with whom we live and work together (Lombardo, 2016; Kokemuller, 2016).

In Latvia, due to the country's geographical location the multicultural environment and society have traditionally developed over the centuries. In 2018, the total population of Latvia was close to 2 million inhabitants of which 62.2\% - Latvians, 25.2\% Russians, 3.2\% Belarusians, 2.2\% Ukrainians, 2.1\% Poles, 2.6\% Roma and other nationalities. Moreover, 58153 or $3.01 \%$ were foreigners and 173 or $0,01 \%$ stateless individuals. Citizens from other countries also live in Latvia, most of whom were from neighboring countries: Russia (41894), Ukraine (3886), Lithuania (3086), Belarus (1891), Estonia (689). But the multicultural environment in Latvia is also enriched by citizens from further countries - India (767), Uzbekistan (620), Germany (426), Poland (280), UK (283), Italy (211), China (204), United States (201), Turkey (108), etc. (Central Statistical Bureau of Latvia, 2018).

Changes to the traditional multicultural environment are a challenge for education, as the need for skills that are not solely related to the specific knowledge and skills of a subject, but are transversal skills or non-technical skills, is becoming more pressing. Non-technical skills are needed in the globalized world, and particularly for its economic development, not only as the basis for mutual integration of knowledge and creative activity, but also for innovation.

The aim of the article is to analyze the assessment of non-technical skills in a multicultural society at different stages of education (for pupils and students) and in the workplace (for teachers and other professionals). A survey of 257 respondents was conducted for this purpose. 


\section{Methodology}

\section{Non-technical skills}

Non-technical skills are defined as a set of a person's cognitive and social skills. These skills are expressed and integrated with technical or subject skills. Non-technical skills are used and manifest themselves in both day-to-day work and emergency situations (Flin at all, 2006). Analysis of accidents and routine work helps to understand how non-technical skills affect the workplace and people (Flin, Maran, 2015). Non-technical skills consist of the following skill set (Bankovics, 2017):

- decision-making skills characterized by identification of the problem, choice of solution, risk assessment;

- the ability to cooperate in a team characterized by transfer of information and communication, development of positive relationships, response to conflict situations;

- the ability to assess the process and results as a whole characterized by awareness of work or training systems, environmental awareness, and analysis of events and causation;

- team management skills characterized by the ability to take on initiative, compliance with standards or defined procedures, operational planning and coordination;

- self-control skills characterized by stress response, concentration capacity and appropriate behavior.

Whereas, Mr. Yoko (2015) defines transversal skills or non-technical skills as the following skill set:

- critical and innovative thinking, characterized by creativity, gumption, ingenuity, informed decision-making, reflective thinking, ability to apply knowledge;

- interpersonal skills characterized by presentation, communication and organizational skills, leadership, teamwork skills, cooperation, initiative, collegiality, sociality;

- intrapersonal skills characterized by self-discipline, enthusiasm, self-motivation, persistence, flexibility and adaptability, risk assessment, compassion, honesty, trust;

- global citizenship characterized by awareness, tolerance, openness, respect for diversity, intercultural understanding, capacity to deal with conflicts, civic participation, respect for the environment;

- choice skills, such as physical and mental health, characterized by healthy lifestyle and nutrition, empathy, self-respect, physical preparedness; or media and information literacy, characterized by the ability to obtain information from media, IT, libraries and archives, participation in democratic processes using media and IT, ability to analyses and evaluate media content etc. (Yano, Mann, 2015).

A. Ribakova, I. Millere and L. Deklava, after carrying out a study on the evaluation of the non-technical skills of operation nurses, conclude that there is a possibility of statistically significant differences between the assessment and realization of the non-technical skills of the operations nurses and surgeons' expectations, which appear in terms of work conditions, communication and teamwork. Surgeons' expectations relate to nurses' ability to exchange information, coordinate their activities with the team and plan their work by setting priorities (Ribakova, Millere, Deklava, 2014).

A. Bankovics points out that today even the skillset of an emerging ship manager does not confine itself with the ability to handle technical devices. One must be able to work with other colleagues in a multicultural environment, quickly assess the situation, think critically and 
make appropriate decisions. Thus, a competent professional readiness is achieved only when the emerging ship manager is able to integrate technical knowledge and non-technical knowledge into his professional activity (Bankovics, 2017).

The acquisition of non-technical skills or transversal skills plays a major role in the educational reform in Latvia (Skola 2030), which is gradually being introduced in all levels of education from September 1st, 2019, and will result by 2023. Non-technical or transversal skills are defined as such skills, which include important cognitive, affective and social aspects of student activity, covering all human activities. Transversal skills help acquire knowledge in different contexts and through different thinking and self-guided learning techniques, thereby strengthening the linkage of new knowledge with personal experience. The use of non-technical skills or transversal skills strengthens the ability of pupils to use them independently and in a variety of situations, including complex and unpredictable ones (Skola 2030, 2018).

Essential non-technical skills or transversal skills include:

- self-awareness and self-leadership, characterized by understanding of own desires, needs and interests; the ability to manage your feelings, develop positive relationships, set realistic goals, take responsible decisions; the ability to learn and develop yourself constantly and independently; understand the process of learning;

- thinking and creativity, characterized by the ability to identify, analyze, assess situations and information and take appropriate action;

- collaboration and participation, characterized by skills to develop sustainable social habits in communication and interaction with fellow individuals, focusing on the overall, shared aim and result, the ability to negotiate, to communicate and cooperate in heterogeneous groups, and the skills to jointly address controversial and complex challenges affecting society's present, future and sustainable development without endangering future generations. and their needs;

- digital skills characterized by the ability to understand the role of digital technologies in the construction of reality, the ability to self-directly apply digital technologies in order to reproduce and construct knowledge and to address challenges.

On the basis of the theoretical analysis of the content of non-technical skills or transversal skills, some specific skills were selected for further research: communication skills, collaboration skills and decision-making skills.

\section{Communication skills}

Communication skills are defined as the ability to address others clearly, coherently and effectively, achieving the set objective. The need for communication skills, relevance and spectrum of applications are increasing rapidly. The process of globalization and internationalization creates an increased demand for citizens who are able to communicate in a multicultural environment. Communication skills, both verbal and written, are the basis for full personal development (Rodríguez Fuentes, 2017).

These skills are developed in various dimensions. It is developed, firstly, in the acquisition of knowledge (theoretical understanding), secondly, in doing (skills and capabilities), thirdly, being (desire or attitude) and, finally, in the desire to do (motivation), 
taking into account the social, cultural, spatial and temporal contexts (Rodríguez Fuentes, 2017).

As one of the goals of developing non-technical skills or transversal skills, particularly communication skills, in higher education, is to prepare a student for the role of an effective employee and a responsible citizen (Dunbar, Brooks, Kubicka-Miller, 2006) in a global environment. The importance of communication skills (for science graduates) is constantly emphasized by educators, employers and professionals in the industry (Spies, Xu, 2018).

For example, if nurses want to provide professional care, they must be able to communicate well with patients, families, doctors and other healthcare teams and representatives. Communicating with patients is the most important aspect of professional activity, each failure can have a negative impact both on patient safety and on the professional performance of a nurse and other health professionals (Liu, Wong, Xue, Xu, 2007).

Communication skills are taught various high school programs (Dunbar, Brooks, Kubicka-Miller, 2006). Oral communication, which is not only the most relevant component in communication and collaboration but also plays an important role in student academic achievements, is particularly important (Spies, $\mathrm{Xu}, 2018$ ). Communication skills, both oral and written, contribute to the individual's integration into today's multimodal communications environment - digital and "face-to-face". Soft-skills, particularly communication skills, are considered absolutely necessary for university graduates and have a significant impact on their employment opportunities (Kaburise, 2016). The development of communication skills is also intended in the content of school curriculum.

\section{Decision-making skills}

Making a decision is a choice between multiple options and is considered a cognitive process. While decision-making skills can be developed at different ages, independent decision-making skills are developing particularly at a young age (Truong, Hallinger, Sanga, 2016). Child decision-making strategies are far more inefficient than for young adults and adults. The child's decision-making skills are most fundamentally affected by the lack of ability to distinguish priorities, important and unimportant questions (Nicolaou, Korfiatis, Evagorou, Constatinou, 2009).

Decision-making is complex and is not possible to achieve without advanced troubleshooting skills and critical thinking. A key prerequisite for decision-making skills is the ability to judge the causes, consequences, benefits and disadvantages of the problem, and the ability to seek different alternatives. The inquiry-based learning environment is considered appropriate for the development of decision-making skills (Nicolaou, Korfiatis, Evagorou, Constatinou, 2009).

Decision-making is the most significant skill in the study process and career selection. It is one of the most important prerequisites and core components in the implementation of sustainable education (Gresch, Hasselhorn, Bogeholz, 2013). 
The role, skills, knowledge, experience and nature of the individual should be mentioned among the factors affecting decision-making (Truong, Hallinger, Sanga, 2016). The decision-making situation often consists of various options that can be identified before decisions are taken (Gresch, Hasselhorn, Bogeholz, 2013). The ability to decide is particularly important and complex in extreme and unpredictable situations. As the environment becomes more multicultural, decision-making factors, such as the informative base for decision-making, are also changing. This significantly complicates decision-making and reiterates the need for this skill.

\section{Collaboration skills}

For collaboration to take place, there has to be motivation and space for development. Collaboration is characterized by the joint objectives and capacity of the participants to operate at a similar level of development (Oliveira, Tinoca, Pereira, 2011). As the global environment changes rapidly, digital platforms have become particularly important in recent years, particularly social networks, which provide collaboration opportunities and create the demand for collaboration skills. The everyday use of collaboration skills in the physical environment has been complemented by the use of these skills digitally, cooperating for both educational purposes and as part of professional activity. Developed networking skills, maintaining a collaboration relationship and the ability to make joint team decisions, is seen as an essential skill in order to be prepared for the challenges of the 21st century. This type of collaboration skills is considered to be an essential learning outcome (Khlaisang, Mingsiritham, 2016). In order to develop these skills, pupils and students should engage in international group work and work together through via digital platforms, enabling them to develop collaboration skills working closely with students and pupils from other countries and nationalities (Oliveira, Tinoca, Pereira, 2011).

Although collaboration skills in the digital environment are a challenge of this century, the development of these skills can also be promoted in the traditional learning environment, using such methods as group work. collaboration through intensive interaction and communication is an important element of group work (Khlaisang, Mingsiritham, 2016). This form of work is effective; teachers of higher education specifically stress the role and effectiveness of small groups in improving collaboration skills. However, in spite of the experience of well-endowed group work, some students do not change attitudes regarding group work and continue to prefer individual work instead (Bernier, Stenstrom, 2016). Collaboration skills are best developed by long-term projects with far more opportunities to develop these skills, particularly projects that are fully structured by students (Moore, 2016).

H. Lee, J. Janssen and T. Wubbels, by applying grounded theory, identified three common barriers to collaboration: lack of pupil or student collaboration skills, "free-ridding" and friendship (Lee, Janssen, Wubbels, 2017).

A large proportion of employers believe that an employee must have excellent collaboration skills to perform their duties (Sugar, Hoard, Brown, 2012). The ability to communicate orally is an essential component of collaboration skills in the workplace (Spies, $\mathrm{Xu}, 2018)$. In the multicultural community, awareness and openness, tolerance and respect for have become a necessary prerequisite for collaboration. 
In order to explore how pupils, students, teachers and other professionals assess their personal communication, decision-making and collaboration skills and intentionally develop these set of skills in the multicultural modern society, a survey with 70 pupils, 107 students, 11 teachers and 69 other professionals (a total of 257 respondents) was conducted in April and May, 2019.

\section{Results and Discussion}

Results of the empirical study show that all groups of respondents (pupils, students, teachers and other professionals) assess their non-technical or transversal skills to communicate, make decisions and collaborate as good and very good (see Figure 1). Moreover, ratings for communication and collaboration do not differ significantly. Meanwhile, decisionmaking skills are considered of poorer strength. Thus, a problem emerges that requires further research, because for collaboration one needs not only fluent communication, but also adequate decision-making skills. On the other hand, efficient collaboration enables the group to make better decisions than each person individually (Surowiecki, 2005). Every individual needs to make various decisions every day. First of all, how to choose partners or how to participate in existing teams, how to implement this collaboration in the global multicultural environment, how to choose the best ways of gathering the necessary information, how to analyze and use it, etc. 


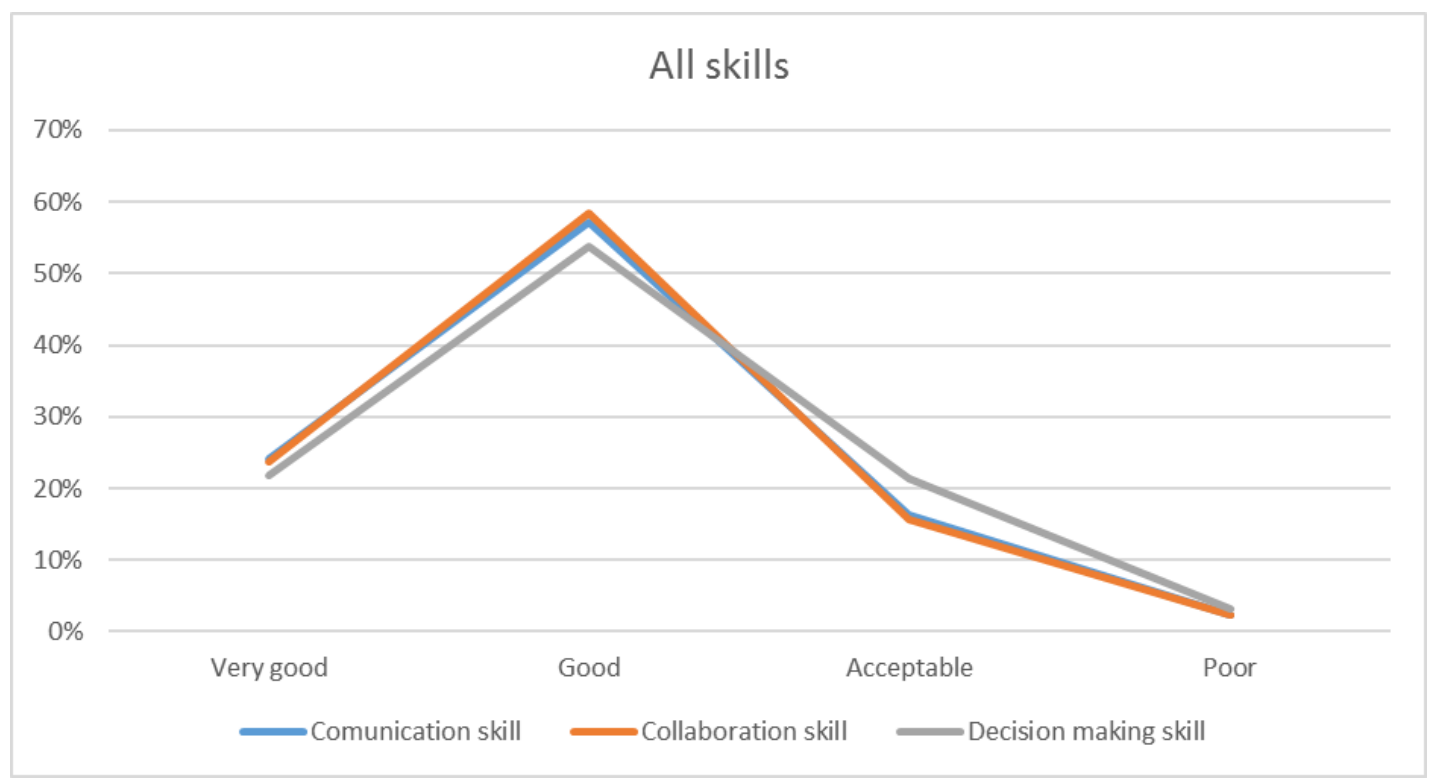

In a more detailed analysis of the assessment of non-technical skills or transversal skills for each group of respondents, some differences may be observed. For example, only teachers assess their communication skills as good and very good - 100\% (see Figure 2). It may be linked to the nature of their work, as communication skills for teachers are essential and applied day-to-day. Thus, perhaps in a way of teachers may have the greatest experience regarding the application of communication skills in today's multicultural environment.

Figure 2. Communication skills

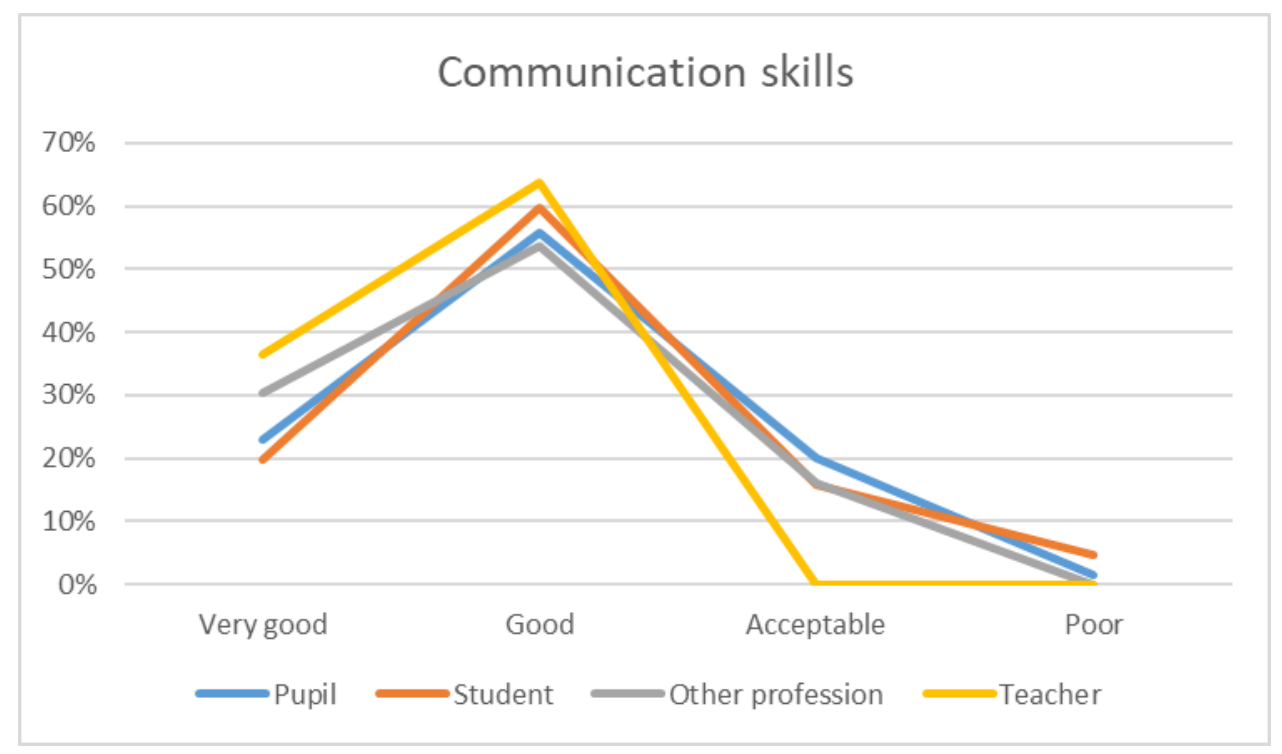

Other groups of respondents show different results. One of most surprising findings is that students assess their communication skills as sufficient (16\%) and weak (5\%), while $14 \%$ pupils assess the same skill as sufficient and as weak $-3 \%$ or 1 pupil. This may be due to the organisation of the learning process, where presently due to rapid intrusion of technology in 
universities, colleges and schools, pupils and students are pressed to work more on the web and e-platforms, and communicate face-to-face far less, moreover, they are given fewer opportunities to speak in group work and publicly in audiences or classes. This requires deeper research.

In the meantime, $16 \%$ of other professionals have assessed their communication skills as satisfactory. None have assessed this particular skill as weak. This self-evaluation may be linked to the diversity of these professions and job responsibilities in today's multi-cultural environment, where conditions for the use of communication skills do not always exist.

Teachers and other professionals assess their personal decision-making skills similarly: from very good to satisfactory (see Figure 3). Moreover, none of them are judged as weak. Other $87 \%$ of other professionals rank their decision-making skills as good and very good, while teachers $-91 \%$. Active professional activity in any profession requires decisions to be taken both individually and in collaboration with groups or teams, thus contributing to the decision-making experience of each employee in the diverse multi-cultural working environment.

Figure 3. Decision-making skills

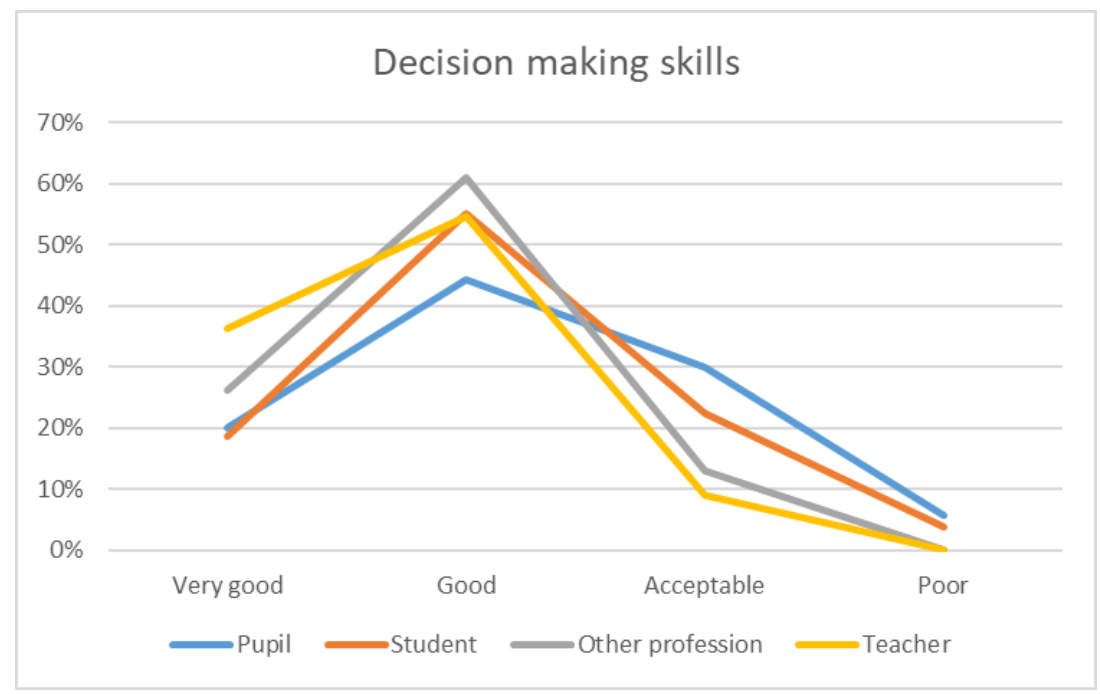

Meanwhile, $11 \%$ of pupils and $4 \%$ of students assess their decision-making skills as weak. Only $30 \%$ of pupils and $22 \%$ of students rank their decision-making skills as satisfactory. This is in line with the study conducted in schools by M. Balode where she concludes that a teacher applies leadership and takes responsibility regarding anything in a classroom and doesn't share it with pupils, thus not contributing to the pupils' decision-making experience. The school objectives and teaching methods are chosen by the teacher, and pupils have the option to choose their own ways of solving tasks, but the teacher's techniques dominate (Balode, 2016). The situation may be altered in the teaching and learning process by choosing more methods, tasks, problems where pupils and students must choose the appropriate means of solution and implement them without supervision. Teachers need to accept the diversity of problem solutions. Educational establishments bring together individuals representing different 
cultures. This diversity merely enriches the experience of every member, enhances his or her decision-making skills.

$76 \%$ of pupils and $78 \%$ of students assess their collaboration skills as good and very good. Thus, $3 / 4$ of modern young people are able to interact with others in different areas of human activity, which is important in today's globalized world. However, $8 \%$ of pupils and 3\% of students admit that their collaborative skills are weak. Therefore, teachers should seriously reflect on how to make more use of a set of techniques in the learning process that requires the collaboration of pupils or students. Any skill may be improved with frequent use. Collaboration skills are not an exception in this respect.

Both teachers and other professionals have not assessed their collaborative skills as weak. $72 \%$ of teachers and $87 \%$ of other professions rank their collaborative skills as good and very good. It is a feature of the modern workplace in a multi-cultural society where there is a need for continuous mutual collaboration.

Figure 3. Collaboration skills

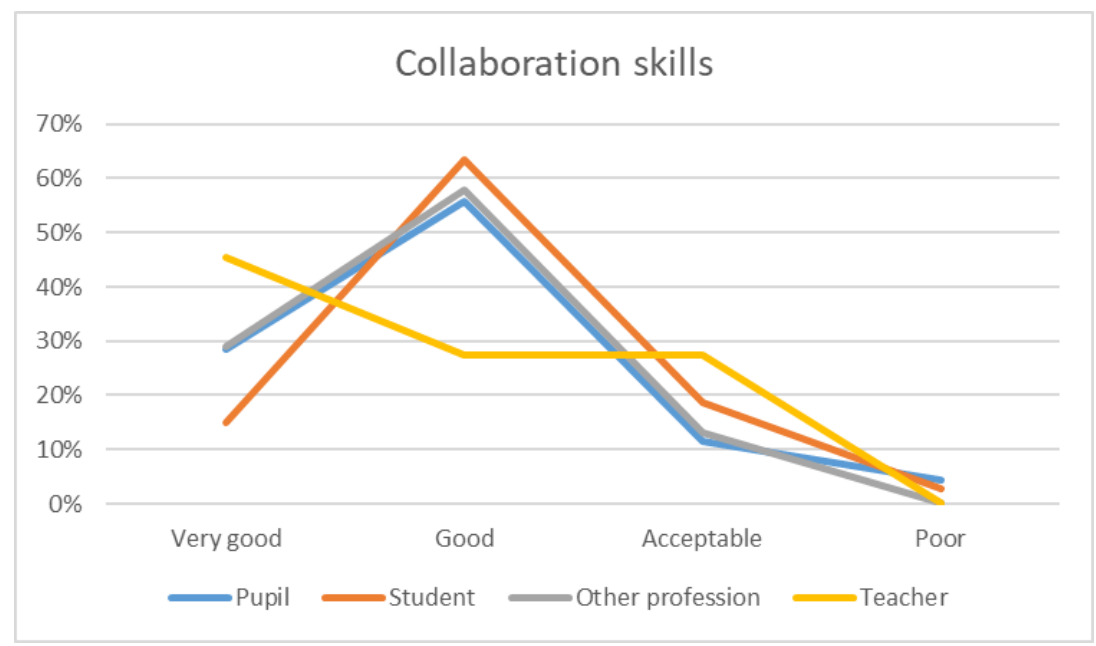

The acquisition of transversal or non-technical skills takes place during day-to-day in a learning environment and workplace in today's multi-cultural society. As with any skill, one is more successful in developing these skills if it is done purposefully. In the study, $62 \%$ of pupils and students respond that they develop their communication, decision-making and collaboration skills consciously (see Figure 4). The same is dome by $42 \%$ of other professionals, but only $36 \%$ of teachers. This may be due to the fact that teachers use these skills as part of their day-to-day work; by constantly applying them they develop the skill and also develop a certain experience in the use of these skills, feeling that they freely manage the skill. However, a risk lies in the changing multicultural environment and globalizing the world - altering learning and technology habits of the new generation may mean that the experience of the use of non-technical or transversal skills of teachers may not meet the needs of today's world. Therefore, further research is needed regarding this problem. 


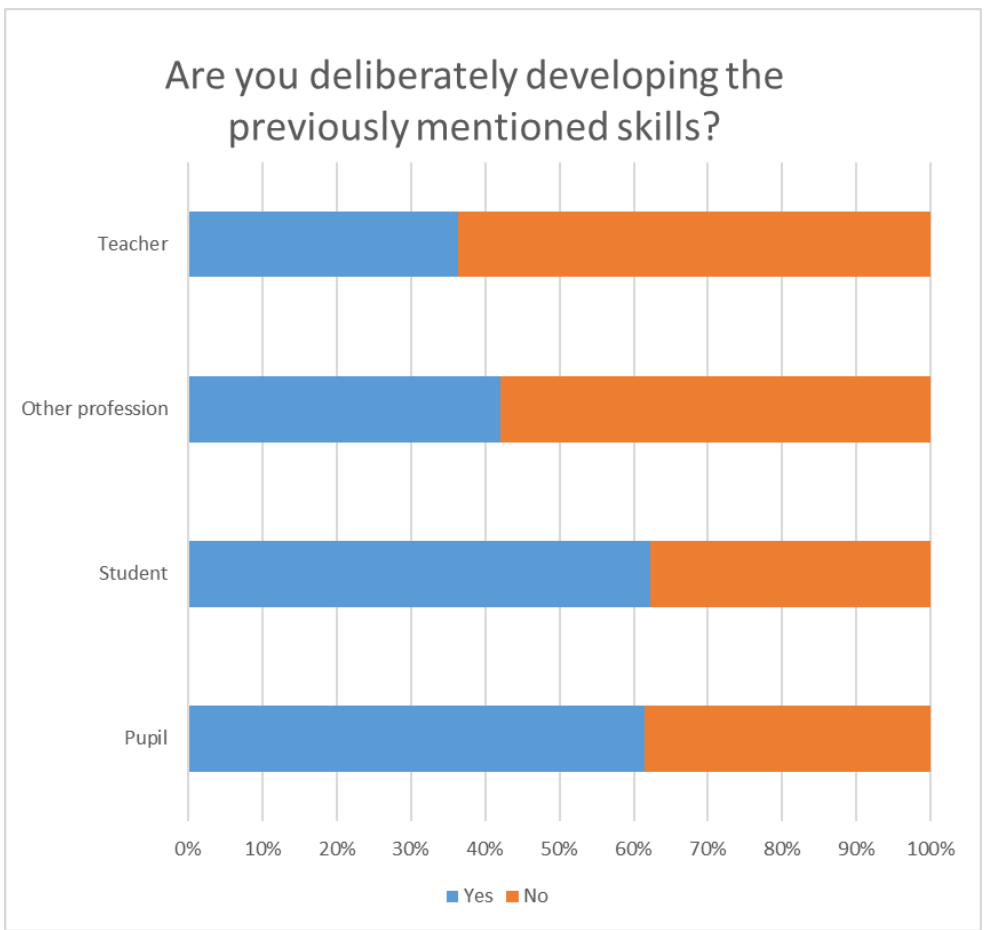

By analyzing the methods used by pupils, students, teachers and other professionals to deliberately develop their communication, decision-making and collaboration skills, as demonstrated by the free response of the survey, it could be concluded that pupils mostly use active communication with other people, participate in group work, various seminars, even at school conferences, tend to make self-decision decisions as often as possible, etc.

Students most often use daily communication for the purposes of informed development of these skills by learning special courses/articles, reading books that provide knowledge used day-to-day and in the study process, preparing presentations, engaging in social events, managing group or team work, etc.

Teachers point out the deliberate development of their skills to communicate, make decisions and collaborate in day-to-day work. In turn, other professionals deliberately develop these skills by attending further training courses.

\section{Conclusion}

Today's multi-cultural environment consists not only of traditional ethnic and cultural groups, but also groups affected by migration processes. In such a contemporary multicultural environment, the non-technical or transversal skills of each individual are increasingly important, contributing to the use of knowledge in a variety of life situations where people compete among others not only with professional skills but also with character traits and nontechnical skills. 
Non-technical skills or transversal skills contain skills that are important in today's multi-cultural environment, such as communication, decision-making and collaborative skills. Pupils, students, teachers and other professionals generally assess their personal communication, decision-making and collaboration skills as good and very good.

The study results indicate that the development of non-technical skills takes place throughout the lifetime from the school bench to the workplace. Pupils and students do not assess their personal non-technical skills or transversal skills highly, but deliberately develop them through learning, through cooperation with others, in the performance of work duties, etc., adults assess their communication, decision-making and collaboration skills higher.

However, the study has highlighted a number of problems that need to be addressed in future studies.

1) $21 \%$ of students and $17 \%$ of pupils have assessed their communication skills as satisfactory and weak. This may be linked to the organization of the learning and study process, where more time should be devoted directly to communication between pupils and students, presentation, debate in the multicultural environment, etc.

2) Only 59\% of pupils have assessed their decision-making skills as good or very good, while $11 \%$ feel they are weak. At the same time, $91 \%$ of teachers value their decisionmaking skills as good and very good. Students deliberately seek to develop their decision-making skills by performing them as often as possible. Therefore, teachers should create more learning situations where pupils need to take their own decisions by choosing their own troubleshooting techniques, targeting their learning habits, etc.

3) $24 \%$ of pupils and $22 \%$ of students assess their personal collaboration skills as satisfactory and weak, but only $9 \%$ of teachers value them as satisfactory. A certain contradiction appears. The learning process should provide an equal space for collaboration for both teachers and pupils and students, jointly developing collaboration experiences in today's multi-cultural environment. The results of the study show a slightly different scene. In practice, teachers are more likely to regard collaboration as managing pupil or student learning. Teachers recognize that collaborative skills are developed mainly in the working environment, while pupils and students are deliberately developing them into groups or teams, involving different social projects, etc. They understand that collaborative skills will be needed in further professional activities, which will be heavily influenced by globalization processes, by the increasing development of multi-cultural societies.

\section{References}

[1] Balode, M. (2016). Partnership between Teacher and Secondary School Student through Learning Mathematics. SOCIETY. INTEGRATION. EDUCATION. Proceedings of the International Scientific Conference. Volume II, pp. $24-33$ 
[2] Bankovičs, A. (2017). Topošo kuğu vadìtāju netehnisko prasmju apguves process jūrniecības augstskolā. Promocijas darbs. Available: https://dspace.lu.lv/dspace/bitstream/handle/7/45956/298-61285Bankovics_Arnis_ab17315.pdf?sequence $=1 \&$ isAllowed $=y$

[3] Bernier, A., Stenstrom, C. (2016). Moving from chance and "chemistry" to skills: Improving online student learning outcomes in small group collaboration. Education for Information, 32(1), pp. 55-69.

[4] Central Statistical Bureau of Latvia. (2018). Demography 2018. Collection of Satatistics. Riga: Central Statistical Bureau of Latvia

[5] Cooper, R. (2003). The Breaking of Nations. Order and chaos in the twenty-first century. London: Atlantic Books

[6] Dunbar, N., E., Brooks, C., F., Kubicka-Miller,T. (2006). Oral Communication Skills in Higher Education: Using a Performance-Based Evaluation Rubric to Assess Communication Skills. In Innovative Higher Education. 44 (2), pp.3 - 115

[7] Flin, R., Martin, L., Goeters, K. M., Hörmann, H. J., Amalberti, R., Valot, C., Nijhuis, H. (2003). Development of the NOTECHS (non-technical skills) system for assessing pilots' CRM skills. Ashgate Publishing.

[8] Flin, R., Maran, N. (2015). Basic concepts for crew resource management and nontechnical skills. Industrial Psychology Research Centre, University of Aberdeen, King's College, Old Aberdeen; Department of Anaesthetics, Royal Infirmary of Edinburgh.

[9] Gresch, H., Hasselhorn, M., Bögeholz, S. (2013). Training in Decision-making Strategies: An approach to enhance students' competence to deal with socio-scientific issues. International Journal of Science Education, 35(15), pp. 2587-2607.

[10] Kaburise, P. (2016). Improving soft skills and communication in response to youth unemployment. International Journal of African Renaissance Studies - Multi-, Inter-and Transdisciplinarity, 11(2), pp. 87-101.

[11] Khlaisang, J., Mingsiritham, K. (2016). Engaging Virtual Learning Environment System to Enhance Communication and Collaboration Skills among ASEAN Higher Education Learners. International Journal Of Emerging Technologies In Learning (IJET), 11(04), pp. 103-113.

[12] Kokemuller, N. (2016). The Definition of Multicultural in the Workplace. California, US. Available http://smallbusiness.chron.com/definition-multicultural-workplace-15469.html

[13] Le, H., Janssen, J., Wubbels, T. (2017). Collaborative learning practices: teacher and student perceived obstacles to effective student collaboration. Cambridge Journal of Education, 48(1), pp. 103-122. 
[14] Liu, J.-E., Mok, E., Wong, T., Xue, L., Xu, B. (2007). Evaluation of an integrated communication skills training program for nurses in cancer care in Beijing, China. Nursing research, 56(3), pp. 202-209.

[15] Lombardo, J. (2016). Cultural Diversity in the Workplace: Definition, Trends \& Examples. Mountain View, Canada. Available http://study.com/academy/lesson/culturaldiversity-in-the-workplace-definition-trends-examples.html

[16] Moore, C. (2016). The Future of Work: What Google Shows Us About the Present and Future of Online Collaboration. TechTrends, 60(3), pp. 233-244.

[17] Nicolaou, C. T., Korfiatis, K., Evagorou, M., Constantinou, C. (2009). Development of decision- making skills and environmental concern through computer- based, scaffolded learning activities. Environmental Education Research, 15(1), pp. 39-54.

[18] Oliveira, I., Tinoca,L., Pereira, A.(2011). Online group work patterns: How to promote a successful collaboration, Computers \& Education 57 (2011), pp. 1348-1357.

[19] Ribakova, A., Millere, I., Deklava, 1. 2014. Operāciju māsu netehnisko prasmju izvērtējums. Politiskās, ekonomiskās, sociālās un tiesiskās sistēmas transformācijas Latvijā un pasaulē. Riga: Stradina University of Riga. Available: https://www.rsu.lv/sites/default/files/imce/Zin\%C4\%81tnes\%20departaments/zinatniskas _konferences/2014/8sekcija/Operaciju_masu_netehnisko_prasmju_izvertejums.pdf

[20] Rodríguez Fuentes, A., Ayllón Blanco, M. F., Gallego Ortega, J. L., Gómez Pérez, I. A. (2017). The Communication Skills of Future Teachers during their Initial Training. Multidisciplinary Journal of Educational Research, 7(1), pp. 88-118.

[21] Skola 2030 (2018) Izglītība mūsdienīgai lietpratībai: mācību satura un pieejas apraksts. Available:

https://domaundari.lv/cepure/Macibu\%20satura\%20un\%20pieejas\%20apraksts.pdf

[22] Spies, T. G., Xu, Y. (2018). Scaffolded Academic Conversations: Access to 21stCentury Collaboration and Communication Skills. Intervention in School and Clinic, 54(1), pp. 22-30.

[23] Sugar, W., Hoard, B., Brown, A., Daniels, L. (2012). Identifying Multimedia Production Competencies and Skills of Instructional Design and Technology Professionals: An Analysis of Recent Job Postings. Journal of Educational Technology Systems, 40(3), pp. 227-249.

[24] Surowiecki., J. (2005). The Wisdom of Crowds. New York: Anchor Books

[25] Truong, T. D., Hallinger, P., Sanga, K. (2017). Confucian values and school leadership in Vietnam: Exploring the influence of culture on principal decision making. Educational Management Administration \& Leadership, 45(1), pp. 77-100. 
[26] Yoko, S. (2015). Transversal Competencies in Education Policy and Practice.

UNESCO, Bangkok Office, Available:

http://unesdoc.unesco.org/images/0023/002319/231907E.pdf

[27] Yano, S., Manns, M. (2015). Asia Shifts From Rote Learning to 21st Century Skills. Education Week. Available:

http://blogs.edweek.org/edweek/global_learning/2015/03/how_asiapacific_education_systems_are_shifting_to_21st_century_skills.html 